\title{
Age related macular degeneration and sun exposure, iris colour, and skin sensitivity to sunlight
}

\author{
J C Khan, H Shahid, D A Thurlby, M Bradley, D G Clayton, A T Moore, A C Bird, J R W Yates, for \\ the Genetic Factors in AMD Study
}

Background/aim: It has been suggested that sun exposure may be a risk factor for age related macular degeneration (AMD) and that skin sensitivity to sunlight and iris colour could be confounding factors. The aim was to investigate this further in the white population.

Methods: 446 cases with end stage AMD were compared with 283 spouse controls. Data on sun exposure, places of residence, iris colour, subjective assessment of change in iris colour, hair colour at age 20 , and skin sensitivity were obtained using a questionnaire. Iris colour was graded clinically by comparison with standard photographs. AMD was graded using stereoscopic colour fundus photographs as well as clinical examination and was defined as the presence of geographic atrophy or choroidal neovascularisation. All variables were included in a multiple logistic regression model including age, sex, and smoking.

Results: There was no association between AMD and sun exposure or related factors except for the suggestion of an association between sunburn prone skin type and geographic atrophy which reached borderline significance. Conclusions: No significant association between AMD and sun exposure, iris colour, change in iris colour, or hair colour was demonstrated.

$\mathrm{E}$ xcessive sun exposure has been proposed as a risk factor for age related macular degeneration (AMD), but this has not been supported by published studies. ${ }^{1-3}$ It has been suggested that skin sensitivity, sun avoidance, iris colour, and change in iris colour may be confounding factors that need to be assessed simultaneously. ${ }^{4}$ To investigate this further, we designed a case-control study which included these factors.

\section{METHODS}

We conducted a case-control study to compare cases of choroidal neovascular membrane (CNV) or geographic atrophy (GA) with spouse controls. Multicentre research ethics committee and local research ethics committee approvals were obtained for the study.

\section{Case-control selection}

Patients with AMD were ascertained from a variety of sources. Subjects were examined by an ophthalmologist (JCK) and completed a detailed questionnaire. All had colour stereoscopic fundus photography of the macular region and photographs were graded according to the International Classification of Age-related Maculopathy and Macular Degeneration; ; the term AMD was reserved for the late stages of CNV and GA. Subjects were over 50 years old and were excluded if they had more than 6 dioptres of myopic refractive error, or evidence of inflammatory or retinovascular disease. Patients were accepted as cases if they were confirmed to have AMD in one or both eyes. Spouses with no or very early changes of age related maculopathy (ARM) were accepted as controls. The control group included subjects with non-extensive small or intermediate drusen and minimal hypopigmentation or hyperpigmentation and matched the criteria for groups 1 and 2 of the AREDS trials. ${ }^{6}$ It was necessary to accept this degree of ARM in controls because of their advanced age. ${ }^{7}$

\section{Variables}

Iris colour was assessed independently by the interviewer and the clinician. Standard photographs were used for comparison based on the grading scheme of Seddon et al. ${ }^{8}$ For analysis the scale was dichotomised to light (grades A and B) and dark (grades $\mathrm{C}-\mathrm{E}$ ). For change in eye colour, patients were given the forced choice of lighter, darker, stayed the same, or don't know. Skin sun sensitivity (skin type) was based on five levels of the Fitzpatrick sun sensitivity scale ${ }^{9}$ (table 1) and was dichotomised to sunburn prone (I and II) and sunburn resistant (III-V). Hair colour at age 20 was assessed as red, blond, brown, or black and dichotomised to light (red and blond) and dark (brown or black). Sun exposure was determined as the number of years working in an outdoor occupation combined with the number of years when at least 2 weeks were spent undertaking an outdoor leisure activity, to give an overall index in years. Sun avoidance was assessed by asking about wearing of a hat, sunglasses, use of sun screen, seeking shade, or wearing covering clothing and was given a score from 0-5. Further assessments of sun exposure were obtained by asking where subjects had lived during 5 year periods of their life and by recording details of skin tumours. Pack years of smoking was calculated from the average number of cigarettes smoked per day during each decade of life, divided by 20 to give packs per day and multiplied by the total number of years of smoking. ${ }^{10}$

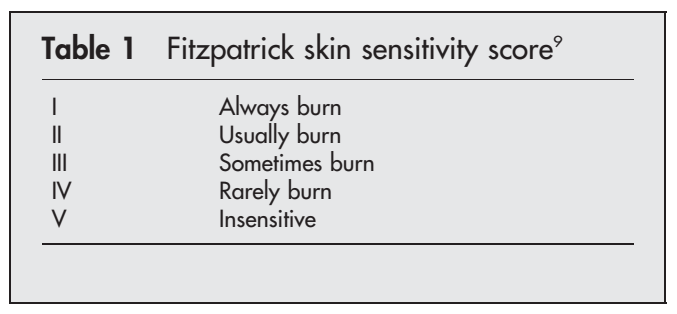

Abbreviations: $A M D$, age related macular degeneration; $A R M$, age related maculopathy; CNV, choroidal neovascular membrane; GA, geographic atrophy 


\begin{tabular}{|c|c|c|}
\hline & $\begin{array}{l}\text { Cases }(n=446) \\
\text { CNV only }(n=269) \\
\text { GA only }(n=107) \\
\text { Mixed GA/CNV }(n=70)\end{array}$ & Controls ( $n=283$ ) \\
\hline Mean age (years (SD)) & $80.3(6.9)$ & $75.6(7.6)$ \\
\hline \multicolumn{3}{|l|}{ Sex } \\
\hline Male & $204(45.7 \%)$ & $117(41.3 \%)$ \\
\hline Female & $242(54.3 \%)$ & $166(58.7 \%)$ \\
\hline \multicolumn{3}{|l|}{ Iris colour } \\
\hline Light & $381(87.4 \%)$ & $248(88.3 \%)$ \\
\hline Dark & $55(12.6 \%)$ & $33(11.7 \%)$ \\
\hline \multicolumn{3}{|l|}{ Change in iris colour } \\
\hline Lighter & $87(20.0 \%)$ & $39(13.9 \%)$ \\
\hline Darker & $31(7.1 \%)$ & $19(6.8 \%)$ \\
\hline Same & $317(72.9 \%)$ & $223(79.4 \%)$ \\
\hline \multicolumn{3}{|l|}{ Worked/lived in sunny climate for $\geqslant 5$ years } \\
\hline Yes & 75 (17.2\%) & $36(12.8 \%)$ \\
\hline No & $360(82.8 \%)$ & $245(87.2 \%)$ \\
\hline \multicolumn{3}{|l|}{ Treatment for skin tumour } \\
\hline Yes & $26(6.0 \%)$ & $14(5.0 \%)$ \\
\hline No & $410(94.0 \%)$ & $267(95.0 \%)$ \\
\hline \multicolumn{3}{|l|}{ Skin sun sensitivity (skin type) } \\
\hline Sunburn prone & $133(30.5 \%)$ & $68(24.2 \%)$ \\
\hline Sunburn resistant & $303(69.5 \%)$ & $213(75.8 \%)$ \\
\hline \multicolumn{3}{|l|}{ Hair colour } \\
\hline Light & $107(24.5 \%)$ & $58(20.6 \%)$ \\
\hline Dark & $330(75.5 \%)$ & $223(79.4 \%)$ \\
\hline $\begin{array}{l}\text { Mean sun exposure index (see text for } \\
\text { explanation) (SD) }\end{array}$ & $25.6(28.9)$ & $26.7(31.9)$ \\
\hline \multicolumn{3}{|l|}{ Sun avoidance measures taken } \\
\hline Yes & $390(89.25)$ & $253(90.4 \%)$ \\
\hline No & $47(10.8 \%)$ & $27(9.6 \%)$ \\
\hline \multicolumn{3}{|l|}{ Pack years of cigarette smoking } \\
\hline 0 & 165 (37.0\%) & $112(39.6 \%)$ \\
\hline $0.1-20$ & $125(28.0 \%)$ & $108(38.2 \%)$ \\
\hline $20.1-40$ & $103(23.1 \%)$ & $49(17.3 \%)$ \\
\hline$>40$ & $53(11.9 \%)$ & $14(4.9 \%)$ \\
\hline
\end{tabular}

\section{Data analysis}

Iris grading was validated using a kappa statistic. Validity of the sun exposure index was assessed using independent samples $t$ tests comparing means between those with and those without skin cancer and those who had and had not lived in a sunny climate. Validity of the sun avoidance measure was assessed using $\chi^{2}$ and correlated with skin type. All variables were included in a logistic regression using SPSS version 11.0 software (SPSS Inc, Chicago, IL, USA).

\section{RESULTS}

The study comprised 446 cases with GA or CNV and 283 controls. Data on age, sex, and risk factors are given in table 2 .

The kappa statistic comparing right with left iris colour was 0.99 (95\% CI 0.98 to 1.00). The comparison of clinician and nurse interviewer grading of iris colour using right eyes only, gave a kappa statistic of 0.83 (95\% CI 0.75 to 0.91 ) indicating a good level of agreement. Subsequent analysis was carried out using the clinician grading of the right eye, since this provided the most complete dataset. To validate the sun exposure index we tested for an association between this and the prevalence of skin cancer in the study population. Those with skin cancers were found to have a higher mean sun exposure index of 36.6 (SD 32.0) compared with 25.6 (SD $30.0)$ in those without skin cancer $(p=0.03)$. As expected, subjects who reported living in a sunny climate for at least 5 years had a higher mean sun exposure index of 32.1 (SD 37.7) compared with 25.5 (SD 28.5) in those who had not done so $(\mathrm{p}=0.03)$. To validate the measure of sun avoidance, we tested whether this correlated with skin type and found that $96.2 \%$ of those with light skin type took measures to cover up from the sun compared with $87.7 \%$ of those with dark skin types, which was statistically significant $\left(\chi^{2}=8.7\right.$, $\mathrm{df}=1, \mathrm{p}=0.003$ ).

The results of logistic regression analysis are given in table 3. Age and pack years of smoking were found to be significantly associated with AMD. The only other association was an increased risk of GA in those with sunburn prone skin type, which reached borderline statistical significance $(\mathrm{OR}=1.62 .95 \%$ CI 1.01 to $2.61, \mathrm{p}=0.05)$.

\section{DISCUSSION}

We chose cases with only the late forms of AMD-namely, GA and CNV with photographic grading confirmation. Smoking is a well established risk factor for AMD and therefore a potential confounder in studies such as this. From a detailed analysis of smoking parameters, which we report elsewhere, we have shown that pack years of smoking cigarettes is the measure most strongly associated with risk of AMD and we incorporated this in our logistic regression model. We used a validated iris grading method and the kappa statistic for agreement between different observers was high, comparable with the value of 0.76 reported by Seddon et al. ${ }^{8}$ We were unable to demonstrate an association of AMD with iris colour or a change in iris colour. This is in agreement with the larger case-control studies and population studies that found no association between iris colour and AMD. ${ }^{3} 7^{11-15}$ Three case-control studies have demonstrated an association between light iris colour and macular degeneration. ${ }^{16-18}$ Unlike the present investigation, these studies looked at cases with a broad definition of macular degeneration, which included cases of ARM as well as AMD. The control groups are not clearly defined in two of the studies. ${ }^{17}{ }^{18} \mathrm{Holz}$ et al ${ }^{19}$ demonstrated that although light iris 
Table 3 Multiple logistic regression comparison of cases with controls for iris colour, skin sun sensitivity, and sun exposure as risk factors for $A M D$

\begin{tabular}{|c|c|c|c|}
\hline & \multicolumn{3}{|l|}{ Odds ratio $(95 \% \mathrm{Cl})$} \\
\hline & $\begin{array}{l}\text { All cases }(n=430) \\
v \text { controls }(n=280)\end{array}$ & $\begin{array}{l}\text { All CNV cases }(n=324) \\
v \text { controls }(n=280)\end{array}$ & $\begin{array}{l}\text { All GA cases }(n=172) \\
v \text { controls }(n=280)\end{array}$ \\
\hline \multicolumn{4}{|l|}{ Age } \\
\hline Per year increment & 1.09 (1.07 to 1.12$)$ & 1.09 (1.06 to 1.12$)$ & $1.12(1.08$ to 1.16$)$ \\
\hline \multicolumn{3}{|l|}{ Sex } & $<0.0001$ \\
\hline Male $^{*}$ & 1.00 & 1.00 & 1.00 \\
\hline Female & $1.06(0.73$ to 1.53$)$ & $1.09(0.74$ to 1.61$)$ & $1.13(0.70$ to 1.83$)$ \\
\hline $\mathrm{p}$ Value (two tailed) for sex & 0.77 & 0.67 & 0.62 \\
\hline \multicolumn{4}{|l|}{ Iris colour } \\
\hline Dark* & 1.00 & 1.00 & 1.00 \\
\hline Light & 0.86 (0.52 to 1.42$)$ & $0.75(0.45$ to 1.26$)$ & $1.56(0.75$ to 3.25$)$ \\
\hline $\mathrm{p}$ Value (two tailed) for iris colour & 0.56 & 0.27 & 0.23 \\
\hline \multicolumn{4}{|l|}{ Change in iris colour } \\
\hline Same* & 1.00 & 1.00 & 1.00 \\
\hline Lighter & 1.36 (0.87 to 2.12$)$ & $1.29(0.81$ to 2.07$)$ & $1.38(0.77$ to 2.46$)$ \\
\hline Darker & $1.19(0.64$ to 2.25$)$ & $1.11(0.57$ to 2.16$)$ & $1.64(0.75$ to 3.60$)$ \\
\hline $\mathrm{p}$ Value (two tailed) for change in iris colour & 0.37 & 0.56 & 0.31 \\
\hline \multicolumn{4}{|l|}{ Worked/lived in sunny climate for $\geqslant 5$ years } \\
\hline Yes & 1.00 & 1.00 & 1.00 \\
\hline $\begin{array}{l}\text { Yes } \\
\text { p Value (two tailed) for sunny climate abroad }\end{array}$ & $1.18(0.74$ to 1.89$)$ & $1.19(0.72$ to 1.95$)$ & $1.30(0.73$ to 2.33$)$ \\
\hline \multicolumn{4}{|l|}{$\begin{array}{l}\text { p Value (two falled) for sunny climate abroad } \\
\text { Treatment for skin tumour }\end{array}$} \\
\hline $\mathrm{No}^{*}$ & 1.00 & 1.00 & 1.00 \\
\hline Yes & $0.97(0.48$ to 1.98$)$ & $1.06(0.50$ to 2.24$)$ & 0.85 (0.32 to 2.23$)$ \\
\hline p Value (two tailed) for skin tumour & 0.94 & 0.88 & 0.74 \\
\hline \multicolumn{4}{|l|}{ Skin sun sensitivity (skin type) } \\
\hline Sunburn resistant* ${ }^{*}$ & 1.00 & 1.00 & 1.00 \\
\hline Sunburn prone & $1.24(0.85$ to 1.80$)$ & $1.14(0.76$ to 1.70$)$ & $1.62(1.01$ to 2.61$)$ \\
\hline$p$ Value (two tailed) for skin sun sensitivity & 0.27 & 0.53 & 0.05 \\
\hline \multicolumn{4}{|l|}{ Hair colour } \\
\hline Dark* & 1.00 & 1.00 & 1.00 \\
\hline Light & $1.19(0.80$ to 1.76$)$ & 1.25 (0.83 to 1.89$)$ & $1.26(0.75$ to 2.11$)$ \\
\hline $\mathrm{p}$ Value (two tailed) for hair colour & 0.39 & 0.29 & 0.38 \\
\hline \multicolumn{4}{|l|}{ Sun exposure index } \\
\hline Per unit increment & $1.00(0.99$ to 1.00$)$ & $1.00(0.99$ to 1.00$)$ & $1.00(0.99$ to 1.00$)$ \\
\hline $\mathrm{p}$ Value (two tailed) for sun exposure & 0.42 & 0.44 & 0.29 \\
\hline \multicolumn{4}{|l|}{ Sun avoidance measures undertaken } \\
\hline Yes $^{*}$ & 1.00 & 1.00 & 1.00 \\
\hline No & 1.00 (0.58 to 1.72$)$ & $0.94(0.53$ to 1.68$)$ & $1.14(0.57$ to 2.30$)$ \\
\hline $\mathrm{p}$ Value (two tailed) for sun avoidance & 1.00 & 0.84 & 0.71 \\
\hline \multicolumn{4}{|l|}{ Pack years of smoking } \\
\hline $0^{*}$ & 1.00 & 1.00 & 1.00 \\
\hline $0.1-20$ & $0.82(0.55$ to 1.21$)$ & $0.76(0.50$ to 1.15$)$ & $0.84(0.50$ to 1.40$)$ \\
\hline $20.1-40$ & 1.60 (0.99 to 2.52$)$ & $1.46(0.90$ to 2.39$)$ & $1.74(0.96$ to 3.16$)$ \\
\hline$>40$ & $2.68(1.36$ to 5.29$)$ & $2.42(1.19$ to 4.92$)$ & $3.60(1.59$ to 8.18$)$ \\
\hline $\mathrm{p}$ Value (two tailed) for pack years & 0.001 & 0.003 & 0.001 \\
\hline
\end{tabular}

colour appeared to be a risk factor for ARM, there was no increased risk when considering the patients' own perception of their eye colour at age 20 and from this the authors surmised that the increased risk was actually associated with a lightening in iris colour. In the Blue Mountains Eye Study ${ }^{4}$ an association was detected for blue iris colour alone when compared with all other iris colours in late AMD using multiple logistic regression adjusting for smoking, age, and sex. In this study, combining all other iris grades and comparing with blue we were unable to detect any such association (data not shown).

No differences in reported hair colour at age 20 were found between cases and controls; this is consistent with the findings of Mitchell et al in the Blue Mountains Eye Study. ${ }^{4}$ In a case-control study, Darzins et al reported significantly poorer tanning ability (skin types I or II) in cases with AMD using a univariate analysis. Using the same method of analysis we too were able to demonstrate this association $\left(\chi^{2}=4.4\right.$, df $1, p=0.04$, data not shown), but this ignores possible confounding factors.

This study shows a possible association between poorer tanning ability and GA but with borderline significance in the context of several risk factors being tested. Data from the Blue Mountains Eye Study ${ }^{4}$ indicated increased risk of AMD in those with both greater skin sun sensitivity and in those with reduced skin sun sensitivity; possibly explained by increased biological risk in those with sensitive skin but increased sun exposure in the darker skin category.

We were unable to demonstrate a link between estimated lifetime sun exposure and late AMD and this result is consistent with the findings from other studies. ${ }^{1-3}$ Data from the Beaver Dam Eye Study demonstrated an association with early ARM in men but no association with AMD. ${ }^{2}$ Estimates of sun exposure are notoriously difficult to make. Some authors have used detailed questionnaires to calculate average yearly sunlight hours and combined this with measurements of ambient ultraviolet $\mathrm{B}^{20}$ We were unable to achieve this level of detail because, in contrast with these population studies, the participants in this study were elderly and unable to recall such information with accuracy. Since our estimates of sun exposure were necessarily crude we assessed the incidence of skin cancers as a proxy measure of sun exposure but this also showed no association with AMD. 


\section{CONCLUSION}

In this study we have been unable to demonstrate any association between AMD and sun exposure, iris colour, or change in iris colour. For the GA form of end stage AMD an association with sunburn prone skin reached borderline significance but this could be attributable to multiple testing.

\section{ACKNOWLEDGEMENTS}

The following investigators also contributed to this work as part of the Genetic Factors in AMD Study: SS Bhattacharya, P Bishop, $\mathrm{P}$ Black, Z Butt, NE Day, C Edelsten, A Fitt, DW Flanagan, A Glenn, S Harding, C Jakeman, C Jones, RJ Lamb, A Lotery, V Moffat, C Moorman, A Nicholas, RJ Pushpanathan, E Redmond, T Rimmer. With special thanks to Tunde Peto for directing the fundus photograph grading and Kay-Tee Khaw for advice on the patient questionnaire. We also appreciate the help of the clinic staff and medical photographers at the Addenbrooke's Centre for Clinical Investigation, Cambridge; Ipswich Hospital; Peterborough District Hospital; Moorfields Eye Hospital, London; Norfolk and Norwich University Hospital, Norwich; West Suffolk Hospital, Bury St Edmunds; Queen Elizabeth Hospital, King's Lynn; James Paget Hospital, Great Yarmouth; and Stoke Mandeville Hospital, Aylesbury. Many thanks to all the patients and their families who participated in this study.

This work was supported by a programme grant from the Medical Research Council.

Multicentre Research Ethics Committee, Trent, UK and local research ethics committee approvals from each of the participating units detailed above were obtained for the study.

\section{Authors' affiliations}

J C Khan*, D A Thurlby, H Shahid, D G Clayton, J R W Yates, Department of Medical Genetics, University of Cambridge, Cambridge, UK

M Bradley, Centre for Applied Medical Statistics, Institute of Public Health, University of Cambridge, Cambridge, UK

A T Moore, A C Bird, Institute of Ophthalmology, University College London, London, UK and Moorfields Eye Hospital, London, UK

*Current affiliation: Norfolk and Norwich University Hospital, Norwich, UK

The authors declare no competing interests in the preparation and submission of this manuscript.

Correspondence to: Professor John Yates, Department of Medical Genetics, University of Cambridge, Box 134, Addenbrooke's Hospital, Cambridge CB2 2QQ, UK; jrwy1@cam.ac.uk

Accepted for publication 29 July 2005

\section{REFERENCES}

1 Darzins P, Mitchell P, Heller RF. Sun exposure and age-related macular degeneration. An Australian case-control study. Ophthalmology 1997:104:770-6.

2 Cruickshanks KJ, Klein R, Klein BE. Sunlight and age-related macular degeneration. The Beaver Dam Eye Study. Arch Ophthalmol 1993;111:514-8.

3 West SK, Rosenthal FS, Bressler NM, et al. Exposure to sunlight and other risk factors for age-related macular degeneration. Arch Ophthalmol 1989; 107:875-9

4 Mitchell P, Smith W, Wang JJ. Iris color, skin sun sensitivity, and age-related maculopathy. The Blue Mountains Eye Study. Ophthalmology 1998; 105:1359-63.

5 Bird AC, Bressler NM, Bressler SB, et al. An international classification and grading system for age-related maculopathy and age-related macular degeneration. The International ARM Epidemiological Study Group. Surv Ophthalmol 1995;39:367-74

6 Age-Related Eye Disease Study Research Group. Risk factors associated with age-related macular degeneration. A case-control study in the age-related eye disease study: age-related eye disease study report number 3. Ophthalmology 2000;107:2224-32.

7 Klein R, Klein BE, Linton KL. Prevalence of age-related maculopathy. The Beaver Dam Eye Study. Ophthalmology 1992;99:933-43.

8 Seddon JM, Sahagian CR, Glynn RJ, et al. Evaluation of an iris color classification system. The Eye Disorders Case-Control Study Group. Invest Ophthalmol Vis Sci 1990;31:1592-8.

9 Fitzpatrick TB. The validity and practicality of sun-reactive skin types I through VI. Arch Dermatol 1988;124:869-71.

10 Bernaards CM, Twisk JW, Snel J, et al. Is calculating pack-years retrospectively a valid method to estimate life-time tobacco smoking? A comparison between prospectively calculated pack-years and retrospectively calculated pack-years. Addiction 2001;96:1653-61.

11 The Eye Disease Case-Control Study Group. Risk factors for neovascular agerelated macular degeneration. Arch Ophthalmol 1992;110:1701-8.

12 Vinding T. Age-related macular degeneration. Macular changes, prevalence and sex ratio. An epidemiological study of 1000 aged individuals. Acta Ophthalmol (Copenh) 1989;67:609-16

13 Gibson JM, Rosenthal AR, Lavery J. A study of the prevalence of eye disease in the elderly in an English community. Trans Ophthalmol Soc UK 1985; 104(Pt 2):196-203.

14 Vingerling JR, Dielemans I, Hofman A, et al. The prevalence of age-related maculopathy in the Rotterdam Study. Ophthalmology 1995;102:205-10.

15 Chaine G, Hullo A, Sahel J, et al. Case-control study of the risk factors for age related macular degeneration. France-DMLA Study Group. Br J Ophthalmol 1998;82:996-1002.

16 Hyman LG, Lilienfeld AM, Ferris FL III, et al. Senile macular degeneration: a case-control study. Am J Epidemiol 1983;118:213-27.

17 Weiter JJ, Delori FC, Wing GL, et al. Relationship of senile macular degeneration to ocular pigmentation. Am J Ophthalmol 1985;99:185-7.

18 Frank RN, Puklin JE, Stock C, et al. Race, iris color, and age-related macular degeneration. Trans Am Ophthalmol Soc 2000;98:109-15.

19 Holz FG, Piguet B, Minassian DC, et al. Decreasing stromal iris pigmentation as a risk factor for age-related macular degeneration. Am J Ophthalmol 1994; 117:19-23.

20 McCarty CA, Lee SE, Livingston PM, et al. Ocular exposure to UV-B in sunlight: the Melbourne visual impairment project model. Bull World Health Organ 1996;74:353-60. 